Revista Brasileira de Agricultura Irrigada v.13, nº.1, p. 3169 - 3179, 2019

ISSN 1982-7679 (On-line)

Fortaleza, CE, INOVAGRI - http://www.inovagri.org.br

DOI: $10.7127 /$ rbai.v13n100833

Protocolo 833.19-07/12/2017 Aprovado em 29/03/2019

\title{
DESENVOLVIMENTO INICIAL DE MUDAS DE EUCALIPTO SOB DIFERENTES LÂMINAS DE IRRIGAÇÃO
}

\author{
Lynniker Trés Bernardino ${ }^{1}$, Robson Bonomo ${ }^{2}$, Joabe Martins de Souza ${ }^{3}$
}

\begin{abstract}
RESUMO
Estabelecer relações entre o consumo de água pela cultura do eucalipto e a disponibilidade de água no substrato de cultivo das mudas ou no solo pós-plantio, contribui na predição do potencial produtivo dos plantios florestais. Diante disso, objetivou-se avaliar o desenvolvimento inicial de mudas de eucalipto nas fases de crescimento e rustificação, utilizando lâminas d'água de irrigação e tensão do solo. O experimento foi conduzido em São Mateus - ES, em delineamento inteiramente casualizado, com seis tratamentos, quatro lâminas baseadas na evapotranspiração de referência - ETo $(50,100,200,300 \%$ da ETo) e dois tratamentos na tensão da água no substrato (3 e $6 \mathrm{kPa}) \mathrm{com}$ quatro repetições. Não ocorreram diferenças significativas entre os tratamentos $100,200,300 \%$ da ETo e o de tensão da água no solo de $6 \mathrm{kPa}$ para altura da muda. As mudas tiveram comportamento similar em relação ao crescimento do diâmetro do caule na fase de crescimento, já na fase de rustificação a lâmina de $300 \%$ da ETo, propiciou maior crescimento, resultado esse semelhante para massa seca da parte aérea e de raiz e número de folhas. Concluiu-se que as maiores lâminas de irrigação (300\% da ETo), proporcionaram maior desenvolvimento das mudas, alcançando padrões definidos para a sua expedição e posterior plantio. Manejo da irrigação via tensão de água no solo (3 e $6 \mathrm{kPa}$ ) e $50 \%$ da ETo limitam o desenvolvimento da muda de eucalipto E. grandis vs. E. urophylla - 6064 para fins comerciais e de transplantio.
\end{abstract}

Palavras-Chave: Eucalyptus ssp., irrigação, crescimento, rustificação, qualidade de mudas.

\section{DEVELOPMENT INITIAL OF EUCALYPTUS SEEDLINGS UNDER DIFFERENT IRRIGATION DEPTHS}

\begin{abstract}
Establishing relationships between water consumption by the eucalyptus crop and the availability of water on the substrate of seedling cultivation or post-planting soil, contributes to the prediction of the

\footnotetext{
${ }^{1}$ Mestre em Agricultura Tropical, Programa de Pós-Graduação em Agricultura Tropical do Centro Universitário Norte do Espírito Santo da Universidade Federal do Espírito Santo (CEUNES/UFES). lynnikertb@hotmail.com

${ }^{2}$ Professor Titular do Departamento de Ciências Agrárias e Biológicas, Centro Universitário Norte do Espírito Santo da Universidade Federal do Espírito Santo (CEUNES/UFES), e-mail: robsonbonomo@gmail.com

${ }^{3}$ Pós-doutorando em Agricultura Tropical do Programa de Pós-Graduação em Agricultura Tropical do Centro Universitário Norte do Espírito Santo da Universidade Federal do Espírito Santo (CEUNES/UFES). e-mail: joabenv@gmail.com
} 
productive potential of the forest plantations. The objective of this study was to evaluate the initial development of eucalyptus seedlings in the growth and rustification phases, using irrigation water slides and soil tension. The experiment was conducted in a completely randomized design with six treatments, four slides based on reference evapotranspiration - ETo $(50,100,200,300 \%$ of ETo) and two treatments based on water tension in the substrate $(3$ and $6 \mathrm{kPa})$ with four replicates. There were no significant differences between the treatments 100, 200,300\% of the ETo and the soil water tension of $6 \mathrm{kPa}$ for height of the seedlings. The seedlings had a similar behavior in relation to stem diameter growth in the growing phase, while in the rustification phase the $300 \%$ ETo depth provided higher growth, a similar result for shoot and root dry matter and number of leaves. It was concluded that the larger irrigation slides (300\% of ETo) provided the greatest development of the seedlings, reaching defined standards for their expedition and subsequent planting. Irrigation management via soil water stress (3 and $6 \mathrm{kPa}$ ) and $50 \%$ of ETo limit the development of eucalyptus seedlings $E$. grandis. E. urophylla - 6064 for commercial and transplanting purposes.

Keywords: Eucalyptus ssp., irrigation, growth, rustification, seedling quality.

\section{INTRODUÇÃO}

A área de árvores plantadas para fins industriais no Brasil totalizou 7,74 milhões de hectares em 2014, aumento de 1,8\% em relação a 2013. Os plantios de eucalipto ocupam 5,56 milhões de hectares da área de árvores plantadas no País, o que representa 71,9\% do total, sendo Estado do Espírito Santo a sexta maior área plantada, com aproximadamente 229 mil hectares (IBÁ, 2015).

Diante desse cenário, é crescente a demanda por mudas das espécies que visam atender ao reflorestamento, sendo foco das empresas florestais a busca constante pela qualidade das mudas (SILVA et al., 2015). A avaliação da qualidade das mudas é fundamental para a compreensão do seu desenvolvimento em viveiro, bem como posterior sobrevivência e crescimento no campo (GASPARIN et al., 2014).

Segundo Silva et al. (2015) a fase de crescimento é uma das etapas em que ocorre o maior consumo hídrico dentre todas as outras fases de produção. As pesquisas relacionadas ao consumo de água para a produção de mudas se limitam à determinação da lâmina média necessária durante o ciclo e a sua relação com o substrato utilizado, sem considerar a influência do clima na variação diária da necessidade hídrica da planta (RODRIGUES et al., 2011).
A disponibilidade de água para o desenvolvimento de plantas é um fator fundamental e determinante, sendo que a escassez ou excesso afetam o crescimento das plantas. A rega em mudas florestais durante o plantio e após as primeiras semanas é de reconhecida importância em plantios comerciais, principalmente em épocas cujas condições climáticas não são favoráveis ao estabelecimento e ao desenvolvimento (BUZETTO et al., 2002). As consequências do déficit hídrico em plantios do gênero Eucalyptus sp. são variáveis, dependendo da espécie, do clima e do manejo adotado (SANTOS; SCHUMACHER, 2016).

A avaliação da qualidade de mudas de eucalipto sob diferentes lâminas de irrigação pode servir como ferramenta para a tomada de decisão do manejo de irrigação em viveiros florestais (SILVA et al., 2015).

Diante disso, objetivou-se nesse trabalho avaliar o desenvolvimento inicial de mudas de eucalipto nas fases de crescimento e rustificação, utilizando lâminas d'água de irrigação, com base na ETo diária e na tensão da água no solo medidas com a utilização de tensiômetro a gás.

\section{MATERIAL E MÉTODOS}

$\mathrm{O}$ experimento foi conduzido em uma estrutura construída no campus do Centro 
Universitário Norte do Espírito Santo (CEUNES-UFES). Situado no município de São Mateus - Estado do Espírito Santo, nas coordenadas $18^{\circ} 43^{\prime} \mathrm{S}$ e $39^{\circ} 51^{\prime} \mathrm{W}$, a $39 \mathrm{~m}$ de altitude. De acordo com a classificação climática proposta por Köppen, a região apresenta clima subtropical e subúmido que caracteriza o clima tropical chuvoso, com chuvas de verão, inverno seco e temperaturas elevadas durante todo o ano.

Na Figura 1 são apresentados os dados climáticos do período avaliado.

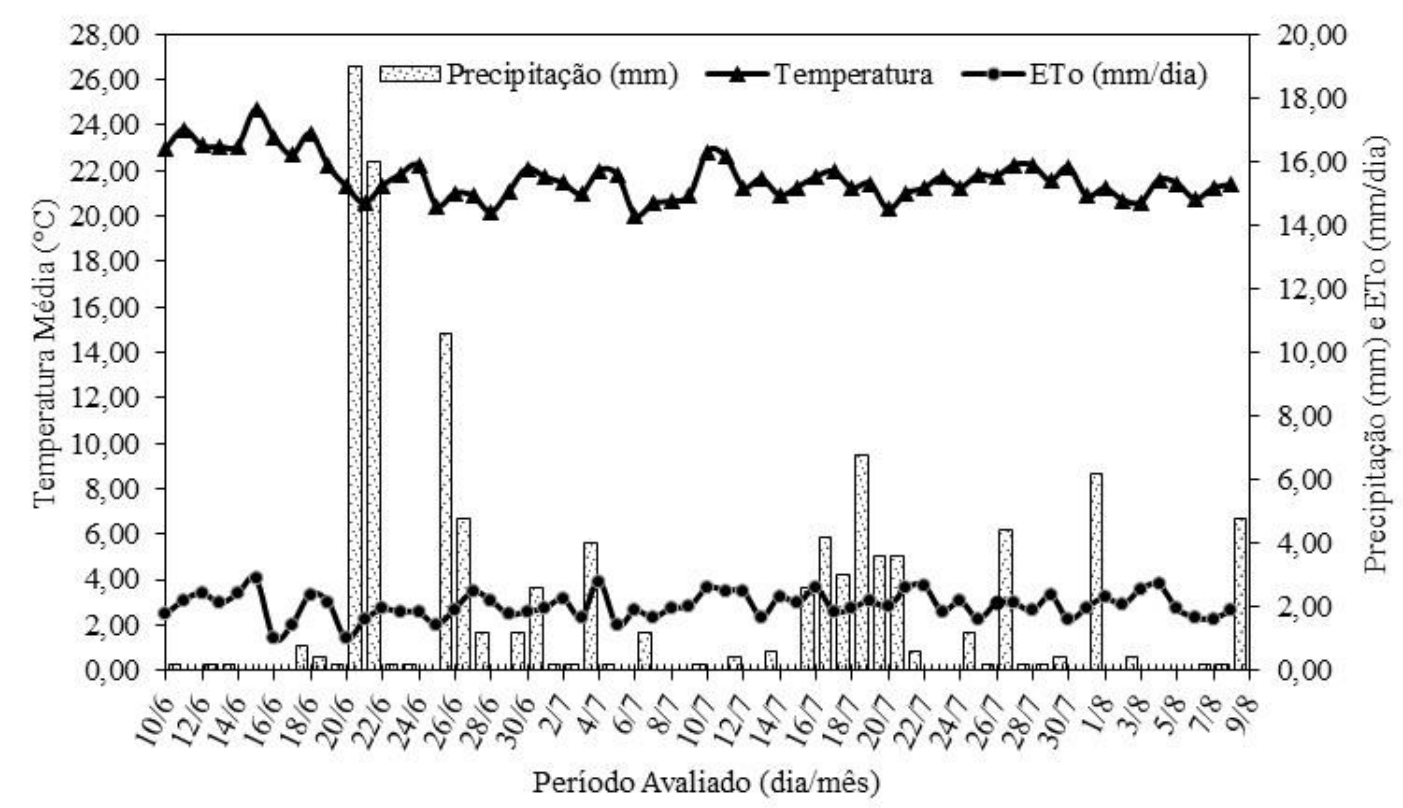

Figura 1. Temperatura, precipitação e evapotranspiração de referência (ETo) no período de 10/06 a 08/08/15, São Mateus - ES.

Foi utilizado o clone híbrido de $E$. grandis vs. E. urophylla - 6064, cultivados nos minijardins clonais protegidos e sob manejo intensivo. A escolha desse clone se deu com base nas atividades das empresas produtoras de celulose que atuam no município de São Mateus/ES.

Esse material possui grande resistência a períodos secos, além de apresentar um bom desenvolvimento inicial. Outra característica importante que este clone apresenta é a facilidade de ser descascado na operação de colheita, facilitando assim a colheita mecanizada.

Foram selecionadas mudas clonais com trinta dias, pois nesta idade as mesmas já superaram as fases de enraizamento e aclimatação.

Como o presente trabalho avalia $\mathrm{o}$ desenvolvimento no crescimento e rustificação das mudas, esta idade de trinta dias se torna ideal. Buscou-se adquirir materiais com $15 \mathrm{~cm}$ de altura, $2 \mathrm{~mm}$ de diâmetro de colo e com dois pares de folhas primárias. O substrato para o plantio das mudas foi composto por uma mistura de $30 \%(\mathrm{v} / \mathrm{v})$ fibra de coco $+35 \%$ $(\mathrm{v} / \mathrm{v})$ vermiculita média $+35 \%(\mathrm{v} / \mathrm{v})$ casca de arroz carbonizada. Acrescentou-se $2,0 \mathrm{~kg} \mathrm{~m}^{-3}$ de osmocote (N-P-K), 10-06-09 + 2,0 $\mathrm{kg} \mathrm{m}^{-3}$ superfosfato simples.

O substrato foi acondicionado em tubetes de polipropileno cilíndricos e uniformes, sem defeitos de fabricação e sem bordas danificadas plástica nos drenos, contendo aproximadamente $53 \mathrm{~cm}^{3}$ da capacidade volumétrica.

$\mathrm{O}$ experimento foi arranjado em delineamento inteiramente casualizado, sendo constituído (para a fase de crescimento) de seis tratamentos, sendo eles: T1 - Reposição de $50 \%$ da Evapotranspiração de Referência (ETo); T2 - Reposição de $100 \%$ da ETo; T3 Reposição de $200 \%$ da ETo e T4 - Reposição de $300 \%$ da ETo; e ainda os tratamentos T5 - 
Tensão da água no solo a 3 kPa e T6 - Tensão da água no solo a $6 \mathrm{kPa}$, sendo que cada tratamento foi composto por quatro repetições. Cada parcela foi constituída de uma bandeja, com 48 mudas de E. grandis vs. E. urophylla 6064 .

O crescimento das mudas ocorreu em local com sombreamento controlado (sombrite $50 \%$ de luz), onde as plantas permaneceram por um período de 30 dias (10/06/2015 a 10/07/2015), com irrigação de acordo com os tratamentos propostos. $\mathrm{Na}$ etapa de rustificação as mudas ficaram por um período de mais 30 dias (11/07/2015 a 08/08/2015) a pleno sol com redução da irrigação. Esta redução seguiu a seguinte proporção: Tratamento $1,2,3$ e 4 , redução de $10 \%$ do valor da ETo a partir do nono dia (20/07/2015) com o decréscimo de mais $10 \%$ do valor inicial a cada sete dias passados, e os tratamentos 5 e 6 , um aumento na tensão da água no solo na ordem de $1 \mathrm{kPa}$, iniciando no nono dia, e a cada sete dias o aumento de mais $1 \mathrm{kPa}$, conforme descrito na Tabela 1 .

Tabela 1. Tratamentos aplicados no experimento durante a rustificação no período de 11/07/2015 a 09/08/2015.

\begin{tabular}{clll}
\hline \multirow{2}{*}{ Tratamentos } & \multicolumn{3}{c}{ Períodos } \\
\cline { 2 - 4 } & 19/07 - 25/07/2015 & 26/07 - 01/08/2015 & 02/08 - 08/08/2015 \\
\hline T1 - 50\% da ETo; & T1 - 45\% da ETo; & T1 - 40\% da ETo; & T1 - 35\% da ETo; \\
T2 - 100\% da ETo; & T2 - 90\% da ETo; & T2 - 80\% da ETo; & T2 - 70\% da ETo; \\
T3 - 200\% da ETo; & T3 - 180\% da ETo; & T3 - 160\% da ETo; & T3 - 140\% da ETo; \\
T4 - 300\% da ETo; & T4 - 270\% da ETo; & T4 - 240\% da ETo; & T4 - 210\% da ETo; \\
T5 - Tensão 3 kPa; & T5 - Tensão 4 kPa; & T5 - Tensão 5 kPa; & T5 - Tensão 6 kPa; \\
T6 - Tensão 6 kPa. & T6 - Tensão 7 kPa. & T6 - Tensão 8 kPa. & T6 - Tensão 9 kPa. \\
\hline
\end{tabular}

Fonte: Autoria própria.

Após o recebimento das mudas de 30 dias, as mesmas foram distribuídas de forma uniforme nas bandejas que compuseram cada parcela. As bandejas possuem as seguintes dimensões: $58,20 \mathrm{~cm}$ de comprimento $\mathrm{x} 41,0$ $\mathrm{cm}$ de largura $\mathrm{x} 16,5 \mathrm{~cm}$ de altura, com espaço para 96 tubetes, as mudas foram distribuídas de forma a sempre alternar um espaço sem mudas, totalizando 48 mudas por bandejas.

A irrigação foi realizada posicionando quatro sprays por bandeja, simulando assim uma microaspersão nas mudas, a uniformidade de aplicação foi realizada com base na metodologia de Christiansen (1942), apresentada por Bernardo et al. (2006). Para a realização do teste, a área em torno de cada tratamento foi isolada e cada parcela foi dividida em uma subárea quadrada situada entre quatro sprays.

Dentro desta subárea distribuíram-se 13 coletores de precipitação. Os coletores foram dispostos nas células das bandejas que seriam ocupadas pelas mudas, desta forma coletando as precipitações em torno dos microaspersores a serem testados.

Os valores encontrados para o Coeficiente de Uniformidade de Christiansen (CUC) e sua respectiva classificação são mostrados na Tabela 2, conforme os tratamentos. 
Tabela 2. Testes de coeficiente de Uniformidade de Christiansen (CUC) realizados antes da realização do experimento.

\begin{tabular}{ccc} 
Tratamentos & \multicolumn{2}{c}{ CUC } \\
\cline { 2 - 3 } T1 - 50\% da Evapotranspiração de Referência (Eto); & $96)^{1}$ & Classificação $^{2}$ \\
T2 - 100\% da Evapotranspiração de Referência (Eto); & Excelente \\
T3 - 200\% da Evapotranspiração de Referência (Eto); & 89,1 & Bom \\
T4 - 300\% da Evapotranspiração de Referência (Eto); & 96,9 & Excelente \\
T5 - Tensão de água no solo 3 kPa; & 96,1 & Excelente \\
T6 - Tensão de água no solo 6 kPa. & 95,4 & Excelente
\end{tabular}

${ }^{1}$ Fonte: Autoria própria. ${ }^{2}$ Fonte: Mantovani et al. (2013).

A lâmina de água diária utilizada para os tratamentos: $\mathrm{T} 1, \mathrm{~T} 2, \mathrm{~T} 3 \mathrm{e} \mathrm{T} 4$ foram determinadas pelo cálculo da evapotranspiração de referência (ETo). A ETo foi estimada pelo método FAO PenmanMonteith (ETo FAO-PM) sendo realizada em conformidade com a parametrização de Allen et al. (1998).

De acordo com a lâmina a ser aplicada se determinava a quantidade de regas que seria realizada, podendo chegar até quatro regas diárias, concentradas nos horários de 08:00, 12:00, 16:00 e 21:00 horas.

Para os tratamentos 5 e 6 , utilizou-se de um dispositivo Irrigás ${ }^{\circledR}$ da Hidrosense, modelo MRI, que consiste em um sensor de tensão de água no solo, que funciona com gás pressurizado nos poros da cápsula cerâmica, chamadas de sensores, que mantém um equilíbrio com o substrato pelo princípio da capilaridade, permitindo o controle automático da irrigação monitorando a tensão da água do solo por dois sensores distribuídos aleatoriamente em dois tubetes, em cada tratamento.

Os sensores foram colocados na altura média do tubete e cobertos por substrato. Sendo assim, a irrigação era aplicada logo que a tensão da água no solo superava um valor crítico de tensão de água para a planta previamente estabelecida. Para monitorar a lâmina diária aplicada, foram utilizados seis coletores de $500 \mathrm{~mL}$ acoplados em gotejadores colocados nas mangueiras de saída de cada tratamento, as medições foram realizadas diariamente.

Com base nessa informação, por proporção, foi possível, determinar à lâmina aplicada em cada tratamento. Avaliação de sobrevivência das mudas foi estimada na forma proporcional, dividindo-se o número de plantas sobreviventes pelo total de plantas de cada parcela (CUSTÓDIO; BARBIN, 2009).

Esta avaliação foi realizada na forma de inspeção visual da parte aérea da muda. Assim, as mudas foram avaliadas em dois períodos: 30 dias após a instalação do experimento, no final da fase de crescimento e 28 dias após o término da fase de crescimento, correspondendo assim ao final do ciclo de rustificação.

As medições do comprimento $(\mathrm{cm})$ total da muda foram feitas a partir da base do caule até inserção da última folha.

Foram medidas oito mudas por parcela, empregando régua graduada em milímetros. Já o diâmetro do caule foi medido na altura do colo da planta, próximas a borda superior do tubete, com auxílio de um paquímetro digital, com precisão de 0,01 milímetros, nessas mesmas plantas foi determinada o número de folhas (NF), pela contagem de todas as folhas presentes na muda.

A determinação da massa seca da parte aérea (MSPA) e da raiz (MSR) foi realizada separando a parte aérea (folhas e caule) do 
sistema radicular por meio de um corte ao nível do substrato. Para retirada do sistema radicular, os tubetes com o torrão foram submersos em água e lavados até a total remoção do substrato.

Em seguida a parte aérea e as raízes foram disposta em embalagens de papel e, posteriormente levadas à estufa de circulação forçada de ar, a temperatura de $65 \pm 5{ }^{\circ} \mathrm{C}$ por 72 horas para obtenção do peso constante. As amostras foram pesadas em balança analítica de precisão $0,01 \mathrm{~g}$.

Os dados obtidos foram submetidos a análise de variância e, quando observado efeito significativo, as médias foram comparadas pelo teste de Tukey a $5 \%$ de significância por meio do Software estatístico ASSISTAT versão 7.7 (SILVA; AZEVEDO, 2016).

\section{RESULTADOS E DISCUSSÃO}

Os valores de lâmina de água aplicada diariamente estimada pela evapotranspiração de referência (ETo) e total, utilizando o método FAO Penman-Monteith (EToFAOPM), encontram-se na Tabela 3 para o período de crescimento e de rustificação das mudas. Foi possível verificar que as lâminas médias diárias acima de $4 \mathrm{~mm}$ foram alcançadas quando realizado manejo acima de $200 \%$ da ETo, obtendo-se uma lâmina média diária máxima de aplicação $9,16 \mathrm{~mm}$. Esses resultados corroboram os de Silva et al. (2015), onde, verificando informações obtidas em viveiros de produtores de mudas de eucalipto, concluíram que a lâmina de irrigação aplicada nesse estádio vegetativo varia de 4 a $16 \mathrm{~mm} \mathrm{dia}^{-1}$, dependendo das condições climática.

Tabela 3. Lâmina de irrigação média diária e total aplicadas nas fases de crescimento e rustificação de mudas do clone híbrido de E. grandis vs. E. urophylla -6064 .

\begin{tabular}{|c|c|c|c|c|c|c|c|}
\hline \multirow{3}{*}{ Fases } & \multirow{3}{*}{ Períodos } & \multicolumn{4}{|c|}{$\%$ ETo } & \multicolumn{2}{|c|}{ Tensão } \\
\hline & & $50 \%$ & $100 \%$ & $200 \%$ & $300 \%$ & $3 \mathrm{kPa}$ & $6 \mathrm{kPa}$ \\
\hline & & \multicolumn{6}{|c|}{ Lâmina Média Diária $(\mathrm{mm})$} \\
\hline Crescimento & $10 / 06-10 / 07 / 2015$ & 1,42 & 2,82 & 5,66 & 8,35 & 2,78 & 1,12 \\
\hline \multirow{4}{*}{ Rustificação } & $11 / 07-18 / 07 / 2015$ & 1,29 & 2,99 & 5,99 & 9,15 & 3,27 & 1,58 \\
\hline & $19 / 07-25 / 07 / 2015$ & 1,29 & 3,02 & 5,68 & 8,50 & 4,42 & 1,80 \\
\hline & $26 / 07-01 / 08 / 2015$ & 1,29 & 1,97 & 3,72 & 5,67 & 1,70 & 0,60 \\
\hline & $02 / 08-08 / 08 / 2015$ & 1,13 & 1,84 & 3,76 & 5,58 & 1,48 & 0,63 \\
\hline & & \multicolumn{6}{|c|}{ Lâmina Total (mm) } \\
\hline Crescimento & $10 / 06-10 / 07 / 2015$ & 42,57 & 84,64 & 169,88 & 250,48 & 83,3 & 33,6 \\
\hline \multirow{4}{*}{ Rustificação } & $11 / 07-18 / 07 / 2015$ & 10,32 & 23,92 & 47,95 & 73,16 & 26,18 & 12,6 \\
\hline & $19 / 07-25 / 07 / 2015$ & 9,03 & 21,16 & 39,73 & 59,52 & 30,94 & 12,6 \\
\hline & $26 / 07-01 / 08 / 2015$ & 9,03 & 13,80 & 26,03 & 39,68 & 11,96 & 4,20 \\
\hline & $02 / 08-08 / 08 / 2015$ & 9,03 & 14,72 & 30,14 & 44,64 & 11,90 & 5,04 \\
\hline
\end{tabular}

Fonte: Autoria própria. * ETo - evapotranspiração de referência

Analisando o índice de sobrevivências das mudas (Tabela 4) após o período de crescimento, os tratamentos $200 \%$ e $300 \%$ da ETo em relação aos demais, apresentaram diferenças significativas quanto a sobrevivência das mudas, mostrando que quanto ocorre aumento da lâmina de irrigação, aumenta-se a sobrevivência da muda no período de crescimento, fato relacionado uma maior disponibilidade de água, tornando mais eficiente os processos fisiológicos da muda, como relatado por Castro et al. (2018) que trabalhando com clone de Eucalyptus grandis, verificaram que o maior conteúdo de água propiciou maior taxa de fotossíntese e de biossíntese da seiva orgânica (hormônios e carboidratos) translocados pelo floema. Ambos os tratamentos apresentaram valores 
superiores a $85 \%$, ou seja, valores significativos em termos de sobrevivência, e que se mantêm de uma fase para outro. O mesmo resultado se repetiu na fase de rustificação onde mesmo com a diminuição das lâminas de irrigação os valores de sobrevivência se mantiveram bem próximos do encontrado na etapa de crescimento, o que demonstra que o efeito de um adequado manejo de irrigação propicia uma baixa ou quase nula variação de sobrevivência entre as fases de crescimento e rustificação de mudas de do clone híbrido de E. grandis vs. E. urophylla -6064 .

Tabela 4. Sobrevivência das mudas do clone híbrido de Eucalyptus grandis x Eucalyptus urophylla -6064, no final do período de crescimento e rustificação.

\begin{tabular}{rcc}
\hline \multirow{2}{*}{ Tratamentos } & \multicolumn{2}{c}{ Fases } \\
\cline { 2 - 3 } & Crescimento & Rustificação \\
\hline T1 - 50\% da ETo & $65,0 \% \mathrm{c}$ & $61,3 \% \mathrm{c}$ \\
T2 - 100\% da ETo & $78,5 \% \mathrm{~b}$ & $76,8 \% \mathrm{~b}$ \\
T3 - 200\% da ETo & $86,0 \% \mathrm{a}$ & $85,8 \% \mathrm{a}$ \\
T4 - 300\% da ETo & $89,5 \% \mathrm{a}$ & $88,0 \% \mathrm{a}$ \\
T5 - Tensão 3 kPa & $77,3 \% \mathrm{~b}$ & $64,5 \% \mathrm{c}$ \\
T6 - Tensão 6 kPa & $62,5 \% \mathrm{c}$ & $47,3 \% \mathrm{~d}$ \\
\hline
\end{tabular}

Médias seguidas pela mesma letra minúscula na coluna não diferem entre si pelo teste de Tukey ao nível de 5\% de significância. Fonte: Autoria própria.

Resultado diferente foi observado por Rodrigues et al. (2011) que trabalhando com muda dos CAF 907 (Eucalyptus urophylla) e o CAF 1117 (Eucalyptus grandis x Eucalyptus urophylla), verificaram que o tratamento com $150 \%$ da ETo, apresentou índice de sobrevivência de $83 \%$, já o tratamento $200 \%$ da ETo, a sobrevivência foi de 90\%. Nos demais tratamentos $(250 ; 300$ e $350 \%$ da ETo), o índice de sobrevivência foi de $100 \%$.

Os menores valores foram verificados na etapa de crescimento nos tratamentos $50 \%$ da ETo e tensão da água no solo de $6 \mathrm{kPa}$, com valores inferiores a $65 \%$ de sobrevivência das mudas. Já para a fase de rustificação o menor valor encontrado foi para o tratamento com manejo de tensão $6 \mathrm{kPa}$ com médias inferiores a $47,6 \%$ (Tabela 4). Ressalte-se que neste tratamento a tensão da água no solo na última semana chegou a $9 \mathrm{kPa}$, valor esse que se mostrou prejudicial às mudas. Acredita-se que a acréscimo semanal de $1 \mathrm{kPa}$ de tensão no substrato, seja, um valor muito elevado, provocando maior mortalidade de plantas. Lopes et al. (2007) descreveram que as perdas entre as fases de crescimento e rustificação, devem ser de no máximo 5\%. Evidenciando assim o manejo inadequado praticado nos tratamentos usando as tensões de água no solo de 3 e $6 \mathrm{kPa}$.

Lopes et al. (2007), estudando os efeitos da irrigação por meio da aplicação de cinco lâminas brutas de irrigação na sobrevivência e nas características fisiológicas de mudas de $E$. grandis produzidas em diferentes substratos, verificaram que o regime hídrico com lâminas diárias inferiores a $5 \mathrm{~mm}$ dia $^{-1}$ não são indicadas para irrigação de mudas de eucalipto quando a temperatura supera os $30{ }^{\circ} \mathrm{C}$ de temperatura média diária, já que a maioria das plantas morre em função do déficit hídrico, fato esse que ocorreu nos tratamentos com menores índices de sobrevivência conforme tabela 3 e 4 . A variável altura na fase de crescimento de mudas todos os tratamentos apresentaram valores na faixa preconizada por Gomes e Paiva (2011), que relatam que as empresas florestais, para a classificação e seleção das mudas de Eucalyptus spp., adotam como um dos parâmetros a altura que de acordo com a região e o sistema de plantio varia entre 15 e $30 \mathrm{~cm}$ (Tabela 5). 
Tabela 5. Altura e diâmetro de caule das mudas do clone híbrido de Eucalyptus grandis $\mathrm{x}$ Eucalyptus urophylla - 6064, no final do período de crescimento e rustificação.

\begin{tabular}{cccccc}
\hline \multirow{2}{*}{ Tratamentos } & \multicolumn{2}{c}{ Crescimento } & & \multicolumn{2}{c}{ Rustificação } \\
\cline { 2 - 3 } \cline { 5 - 6 } & Altura $(\mathrm{cm})$ & Diâmetro $(\mathrm{mm})$ & & Altura $(\mathrm{cm})$ & Diâmetro $(\mathrm{mm})$ \\
\hline T1 - 50\% da ETo & $20,48 \mathrm{bc}$ & $2,40 \mathrm{a}$ & & $20,50 \mathrm{c}$ & $2,68 \mathrm{bc}$ \\
T2 - 100\% da ETo & $21,42 \mathrm{abc}$ & $2,54 \mathrm{a}$ & & $21,49 \mathrm{~b}$ & $2,84 \mathrm{bc}$ \\
T3 - 200\% da ETo & $22,57 \mathrm{a}$ & $2,68 \mathrm{a}$ & & $22,70 \mathrm{ab}$ & $2,91 \mathrm{~b}$ \\
T4 - 300\% da ETo & $22,31 \mathrm{ab}$ & $2,72 \mathrm{a}$ & & $23,05 \mathrm{a}$ & $3,27 \mathrm{a}$ \\
T5 - Tensão 3 kPa & $19,63 \mathrm{c}$ & $2,40 \mathrm{a}$ & & $20,08 \mathrm{bc}$ & $2,58 \mathrm{c}$ \\
T6 - Tensão 6 kPa & $21,36 \mathrm{abc}$ & $2,50 \mathrm{a}$ & & $21,77 \mathrm{~b}$ & $2,59 \mathrm{c}$ \\
\hline
\end{tabular}

Médias seguidas pela mesma letra minúscula na coluna não diferem entre si pelo teste de Tukey ao nível de 5\% de significância. Fonte: Autoria própria.

Ainda segundo Alfenas et al. (2009) um dos critérios para seleção de mudas de eucalipto para expedição, é a variável altura, que de acordo com o padrão estabelecido, pode variar entre 20 a $35 \mathrm{~cm}$. Já, conforme destacado por Xavier et al. (2013), a produção de mudas com altura entre 25 e $30 \mathrm{~cm}$, é considerada como indicador para plantio comercial, resultados encontrados dentro do estabelecido pelos autores.

Observa-se que não ocorreram diferenças significativas entre os tratamentos $100,200,300 \%$ da ETo e o de tensão da água no solo de $6 \mathrm{kPa}$, sendo assim possível constatar que outros fatores influenciaram no crescimento das plantas e a lâmina de água não foi determinante para o desenvolvimento deste parâmetro. $\mathrm{O}$ mesmo comportamento se verifica na fase de rustificação, onde os tratamentos 200 e $300 \%$ ETo se sobressaíram e apresentaram igualdade estatística (Tabela $5)$.

Lopes et al. (2007), avaliando a qualidade de mudas de eucalipto produzidas sob lâminas de irrigação variando de 2 a $6 \mathrm{~mm}$ e dois tipos de substrato, observaram que o incremento em altura foi proporcional ao aumento da lâmina, resultado também observado nesta pesquisa.

Assim, tendo como referência essas informações, constatou nesta pesquisa que todos os tratamentos onde foram aplicadas as lâminas de acordo com a ETo e lâminas de acordo com a tensão de água no solo, as mudas enquadraram-se no padrão de exigência alcançando aos 90 dias as alturas mínimas estabelecidas, sendo assim avaliando apenas a variável altura as mudas estavam adequadas para serem expedidas para campo.

É possível observar que as mudas tiveram comportamento similar em relação ao crescimento do diâmetro do caule na fase de crescimento, sendo suas médias estatisticamente iguais quando analisadas em função do tratamento aplicado (Tabela 5). Resultado que corrobora os de Silva et al. (2015) para o clone Eucalyptus urophylla x Eucalyptus globulus, que da primeira à última avaliação, não apesentou diferenças estatísticas no desenvolvimento do diâmetro das mudas sob os diversos tratamentos com lâminas de irrigação.

$\mathrm{Na}$ fase de rustificação o tratamento $300 \%$ da ETo, com maior lâmina de água aplicado demonstrou um ganho significativo no crescimento do caule diferindo estatisticamente dos demais tratamentos (Tabela 5).

Tal como observado por Tatagiba et al. (2007), que avaliaram o crescimento e produção de clones de Eucalyptus submetidos a diferentes manejos de irrigação e verificaram que a deficiência hídrica restringiu o crescimento do diâmetro do caule.

Lopes et al. (2007) estabeleceram um valor mínimo de $2,5 \mathrm{~mm}$ para variável diâmetro do caule para mudas de E. grandis. Neste trabalho após o período de rustificação, o clone híbrido de E. grandis x E. urophylla6064 , apresentou valor superior, em todos os 
tratamentos, mostrando que o crescimento do diâmetro no período de rustificação foi determinante. Aqueles autores verificaram que, sob lâminas de irrigação de 6 e $8 \mathrm{~mm} \mathrm{dia}^{-}$ 1, o diâmetro do caule obtido foi de $2,19 \mathrm{~mm}$ e que lâminas a partir de $8 \mathrm{~mm} \mathrm{dia}^{-1}$ apresentavam diâmetros maiores de $2,5 \mathrm{~mm}$.

Assim como Xavier et al. (2011) ao estudarem o crescimento do híbrido de $E$. grandis $\mathrm{x}$ E. urophylla sob diferentes níveis de déficit hídrico, verificaram que o crescimento foi mais satisfatório sob maior disponibilidade hídrica e que o diâmetro foi a variável que se mostrou mais dependente da disponibilidade de água.

Analisando os resultados do número de folhas, é possível verificar que tratamentos submetidos a uma lâmina maior de água, apresenta uma maior retenção das folhas. Durante a fase de crescimento o tratamento com $300 \%$ da evapotranspiração de referência
(ETo) apresentou melhor resultado, em contrapartida o tratamento com $50 \%$ da ETo apresentou o pior resultado (Tabela 6).

Esse resultado difere do encontrado por Queiroz et al. (2017) que estudaram a influência do regime hídrico sobre o crescimento de Eucalyptus globulus e verificaram que a lâmina de $75 \%$ da ETo, com média de $4,5 \mathrm{~mm}$ dia $^{-1}$ promoveu o maior número de folhas, diferença essa que está relacionada as diferentes condições edafoclimáticas do estudo, já que para essa lâmina aplicada, foi encontrado para as condições desse trabalho quando realizado o manejo da irrigação com 200 e $300 \%$ da ETo (Tabela 3).

Mostrando a importância dos estudos em diferentes regiões. Os autores também verificaram que as plantas que receberam a profundidade com $175 \%$ do ETo apresentaram valores mais baixos.

Tabela 6. Número de Folhas (NF), matéria seca da parte aérea (MSPA) e seca da raiz (MSR) das mudas do clone híbrido de Eucalyptus grandis x Eucalyptus urophylla - 6064, no final do período de crescimento e rustificação.

\begin{tabular}{|c|c|c|c|c|c|c|}
\hline \multirow{3}{*}{ Tratamentos } & \multicolumn{3}{|c|}{ Crescimento } & \multicolumn{3}{|c|}{ Rustificação } \\
\hline & \multirow{2}{*}{ NF } & MSPA & MSR & \multirow{2}{*}{ NF } & MSPA & MSR \\
\hline & & \multicolumn{2}{|c|}{$\left(\right.$ g planta $\left.^{-1}\right)$} & & \multicolumn{2}{|c|}{$\left(\right.$ g planta $\left.^{-1}\right)$} \\
\hline T1 - 50\% da ETo & $4,25 \mathrm{c}$ & $0,58 \mathrm{c}$ & $0,35 \mathrm{~b}$ & $5,62 \mathrm{~cd}$ & $1,09 \mathrm{bc}$ & $0,43 \mathrm{~b}$ \\
\hline T2 - 100\% da ETo & $5,75 \mathrm{bc}$ & $0,77 \mathrm{abc}$ & $0,54 \mathrm{ab}$ & $6,5 \mathrm{bc}$ & $1,27 \mathrm{abc}$ & $0,60 \mathrm{ab}$ \\
\hline T3 - 200\% da ETo & $7,53 \mathrm{ab}$ & $0,98 \mathrm{ab}$ & $0,52 \mathrm{ab}$ & $7,82 \mathrm{~b}$ & $1,28 a b$ & $0,63 \mathrm{ab}$ \\
\hline T4 - 300\% da ETo & $8,65 \mathrm{a}$ & $1,05 \mathrm{a}$ & $0,71 \mathrm{a}$ & $9,62 \mathrm{a}$ & $1,69 \mathrm{a}$ & $0,77 \mathrm{a}$ \\
\hline T5 - Tensão 3 kPa & $6,21 \mathrm{bc}$ & $0,76 \mathrm{bc}$ & $0,30 \mathrm{~b}$ & $5,25 \mathrm{~cd}$ & $0,73 \mathrm{~cd}$ & $0,45 \mathrm{~b}$ \\
\hline T6 - Tensão 6 kPa & $5,18 \mathrm{c}$ & $0,73 \mathrm{bc}$ & $0,35 \mathrm{~b}$ & $4,87 \mathrm{~d}$ & $0,49 \mathrm{~d}$ & $0,50 \mathrm{~b}$ \\
\hline
\end{tabular}

Médias seguidas pela mesma letra minúscula na coluna não diferem entre si pelo teste de Tukey ao nível de 5\% de significância. Fonte: Autoria própria.

Na segunda fase do experimento durante a rustificação (Tabela 6), mesmo reduzindo as doses de água, os tratamentos com aplicação de lâminas calculadas através da ETo, apresentaram ganho no número de folhas, sendo que o maior número de folhas foi encontrado para o manejo com $300 \%$ da ETo diferindo dos demais. Os tratamentos com aplicação de lâminas utilizando a tensão de água no substrato, sofreram uma desfolha muito grande, isso pode ter ocorrido devido ao aumento nas tensões no solo com acréscimo $1 \mathrm{kPa}$ a cada semana, causando assim um déficit hídrico além do adequado para fins de rustificação, fazendo com que as mudas perdessem folhas, fato relatado por Lopes et al. (2007) em se tratando de manejo hídrico, é esperado que tanto a área das folhas diminua em função do estresse hídrico, bem como o 
número de folhas, como foi o caso desta pesquisa.

Butrinowski et al. (2013), avaliando o comportamento do desenvolvimento foliar do eucalipto, verificaram que as menores disponibilidades hídricas influenciaram negativamente no número de folhas da planta, podendo-se considerar o E. grandis como uma espécie responsiva a maior disponibilidade de água, ainda estes autores verificaram que lâmina de $250 \%$ da ETo apresentou o melhor número de folhas.

Lopes et al. (2007) estabeleceram valor mínimo de três pares de folhas para essa variável em mudas de E. grandis. Neste trabalho apenas os tratamentos 100;200 e $300 \%$ da ETo conseguiriam ter suas mudas expedidas para o campo, pois estes tratamentos apresentaram em média aproximadamente 3,4 e 5 pares de folhas respectivamente.

A matéria seca da parte aérea (MSPA) em função de tratamentos envolvendo diferentes lâminas de irrigação e para as fases de crescimento e rustificação, apresentam melhores resultados nos tratamentos 100; 200 e $300 \%$ da ETo. Vale salientar que esses três tratamentos baseados na ETo são os que apresentam maiores lâminas de irrigação (Tabela 6).

$\mathrm{Na}$ etapa de rustificação os mesmos tratamentos se destacam positivamente, com o mesmo comportamento. Os demais tratamentos, com volumes de água menores, apresentaram valores inferiores, demonstrando que o acúmulo de matéria seca está relacionado com a disponibilidade de água para a planta, resultado semelhante a encontrado por Butrinowski et al. (2013).

Já para variável matéria seca da raiz (MSR), observa-se que as médias dos tratamentos com lâmina de 100, 200 e 300\% da ETo se destacaram nas avaliações ao final de cada fase, seguida pelas médias dos demais. Ainda se verificou que tratamento com 50\% da lâmina evapotranspirada e tensões de $3 \mathrm{kPa}$ e $6 \mathrm{kPa}$ apresentaram menor crescimento radicular, possivelmente devido a menor quantidade de água recebida e, consequentemente, menor disponibilidade de água no substrato (Tabela 6). O resultado é semelhante ao encontrado por Butrinowski et al. (2013), em que os maiores valores de matéria seca foram expressos na maior reposição hídrica $(250 \%$ da $\mathrm{ETo})$, e não apresentou diferença estatística, ao nível de $5 \%$ de significância, entre os tratamentos 50 e $100 \%$ da ETo, sendo indicativo que estes dois tratamentos são limitantes ao desenvolvimento da muda.

Esses resultados são importantes já que a massa da matéria seca da parte aérea e do sistema radicular indicam a rusticidade e correlaciona-se diretamente com a sobrevivência e desempenho inicial das mudas após o plantio no campo de acordo com Gomes e Paiva (2011)

\section{CONCLUSÕES}

Lâminas de irrigação com reposição de $300 \%$ da evapotranspiração de referência, possibilitam obter mudas de eucalipto que atendem os requisitos para expedição e transplantio.

Manejo da irrigação com base na tensão de água no solo (3 e $6 \mathrm{kPa}$ ) e $50 \%$ da ETo limitam o desenvolvimento da muda de eucalipto E. grandis vs. E. urophylla - 6064, para fins comerciais e de transplantio.

\section{REFERÊNCIAS BIBLIOGRÁFICAS}

ALFENAS, A. C.; ZAUZA, E. A. V.; MAFIA, R. G.; ASSIS, T. F. DE. Clonagem e doenças do eucalipto. 2 ed. Viçosa: Editora UFV, 2009. 500p.

ALLEN, R.G., PEREIRA, L.S., RAES, D., SMITH, M. Crop evapotranspiration Guidelines for computing crop water requirements. Rome, FAO, 1998, (Irrigation and Drainage, Paper 56).

BERNARDO, S.; SOARES, A. A.; MANTOVANI, E. C. Manual de irrigação. 8. ed. Viçosa, MG: UFV, 2006. $625 \mathrm{p}$. 


\section{DESENVOLVIMENTO INICIAL DE MUDAS DE EUCALIPTO SOB DIFERENTES LÂMINAS DE IRRIGAÇÃO}

BUTRINOWSKI, R. T.; BUTRINOWSKI, I. T.; SANTOS, E. L.; PICOLOTTO, P. R.; PICOLOTTO, R. A.; SANTOS, R. F. Disponibilidade hídrica no desenvolvimento inicial de mudas de Eucalyptus grandis em ambiente protegido. Acta Iguazu, v.2, n.3, p. 84-93, 2013.

BUZETTO, F.A.; BIZON, J.M.C.; SEIXAS, F. Avaliação de um polímero adsorvente a base de acrilamida no fornecimento de água no fornecimento de água em mudas de Eucalyptus Urophylla em pós-plantio. Piracicaba: IPEF, 2002. 8 p.

CASTRO, V.R.; SURDI, P.G.; TOMAZELLO FILHO, M.T.; CHAIX, G.; LACLAU, J.P. Efeito da disponibilidade hídrica e da aplicação de potássio e sódio no crescimento em diâmetro do tronco de árvores de Eucalyptus grandis. Scientia Forestalis. v.45, n.113, p. 89-99, 2017.

CUSTÓDIO, T. N.; BARBIN, D. Modelos de predição para sobrevivência de plantas de Eucalyptus grandis. Revista Ciência e Agrotecnologia, v. 33, especial, p.1948-1952, 2009.

GASPARIN, E.; AVILA, A. L.; ARAUJO, M. M.; CARNELUTTI FILHO, A.; DORNELES, D. U.; FOLTZ, D. R. B. Influência do substrato e do volume de recipiente na qualidade das Mudas de Cabralea canjerana (vell.) Mart. em viveiro e no campo. Ciência Florestal, v. 24, n. 3, p. 553-563, 2014.

GOMES, J. M.; PAIVA, H. N. Viveiros florestais: propagação sexuada. Viçosa, MG: UFV, 2011. 116 p.

IBÁ - INDÚSTRIA BRASILEIRA DE ÁRVORES. Relatório Ibá 2015: Área de árvores plantadas, Cap.5, p.27, 2015.

LOPES, J. L. W.; GUERRINI, I. A.; SAAD, J. C. C. Qualidade de mudas de eucalipto produzidas sob diferentes lâminas de irrigação e dois tipos de substrato. Revista Árvore, v. 31, n. 5, p. 835-843, 2007.

MANTOVANI, E.C.; BERNARDO, S.; PALARETTI, L.F. Irrigação: princípios e métodos; 3. ed. UFV, 2013, 355p

QUEIROZ, T. B.; PEREIRA, N. N. J.; SILVA, J. C. R. L.; FONSECA, F. S. A.; MARTINS, E. R. Influence of water regime on initial growth and essential oil of Eucalyptus globulus. Ciência Rural, v.47, n.3, P.1-8, 2017.

RODRIGUES, S. B. S.; MANTOVANI, E. C.; OLIVEIRA, R. A.; PAIVA, H. N.; ALVES, M. E. B. Necessidades hídricas de mudas de eucalipto na região centro-oeste de Minas Gerais. Irriga, v. 16, n. 2, p. 212-223, 2011.

SANTOS, K. F.; SCHUMACHER, M. V. Ecofisiologia e crescimento de Eucalyptus em condição de déficit hídrico. Ecologia e Nutrição Florestal, v.4, n.2, p.33-44, 2016.

SILVA, F. de A. S.; AZEVEDO, C. A. V. de. The Assistat Software Version 7.7 and its use in the analysis of experimental data. African Journal of Agricultural Research, v.11, n.39, p.3733-3740, 2016.

SILVA, C. R. A.; RIBEIRO, A.; OLIVEIRA, A. S.; KLIPPEL, V. H.; BARBOSA, R. L. P. Desenvolvimento biométrico de mudas de eucalipto sob diferentes lâminas de irrigação na fase de crescimento. Pesquisa Florestal Brasileira, v. 35, n. 84, p. 381-390, 2015.

TATAGIBA, S. D.; PEZZOPANE. J. E. M.; REIS, E. F.; DARDENGO, M. C. J. D.; EFGEN, T. A. M. Comportamento fisiológico de dois clones de Eucalyptus na época seca e chuvosa. Cerne, v. 13, n. 2, p. 149 - 159, 2007.

XAVIER, A.; WENDLING, I.; SILVA, R. L. Silvicultura clonal: princípios e técnicas. Viçosa, MG: Ed. da UFV, 2013. 279 p. 